\title{
Assessment by radionuclide angiography of right and left ventricular function in chronic bronchitis and emphysema
}

\author{
W MACNEE, QF XUE, WJ HANNAN, DC FLENLEY, CJ ADIE, AL MUIR \\ From the Departments of Medicine, Respiratory Medicine, and Medical Physics and Medical Engineering, \\ University of Edinburgh
}

ABSTRACT Non-invasive measurements of right and left ventricular ejection fraction (RVEF, LVEF) by multiple-gated equilibrium radionuclide ventriculography were performed in 18 control subjects, 16 patients with angina pectoris, and 45 patients with hypoxic chronic bronchitis and emphysema. The mean RVEF in the control subjects was $0.62 \pm 0.09$ (SD), which was not significantly different from the mean RVEF in the patients with angina $(0.60 \pm 0.09)$, but was significantly higher $(p<0.01)$ than the mean value in patients with chronic bronchitis and emphysema $(0.45 \pm 0 \cdot 11)$. LVEF was not significantly different in the groups studied. There was a significant correlation between LVEF and RVEF only in patients with chronic bronchitis and emphysema $(p<0.001)$. Those patients with chronic bronchitis and emphysema who had clinical evidence of cor pulmonale at the time of the study had significantly lower values of RVEF and LVEF ( $p<0.001$ ) than patients with no previous cor pulmonale or those who had had cor pulmonale in the past. There was a significant correlation between RVEF and arterial oxygen ( $p$ $<0.01)$ and carbon dioxide tensions $(p<0.05)$. Reduced RVEF in patients with chronic bronchitis and emphysema may be an early indicator of the development of cor pulmonale and may be useful as a non-invasive method of assessing the effects of therapeutic interventions.

Right ventricular hypertrophy, with pulmonary hypertension, is a characteristic feature of the "blue and bloated" (type B, non-fighter) pattern seen in some patients with chronic bronchitis and emphysema. ${ }^{1-4}$ Although the association between arterial hypoxaemia and pulmonary vasoconstriction is well known, ${ }^{5}$ the mechanism of development of cor pulmonale in these patients is unclear. Cor pulmonale is recognised clinically in patients with chronic bronchitis and emphysema by the presence of peripheral oedema for which no other cause can be found, and it is a poor prognostic sign, only onethird of such patients surviving for five years. ${ }^{46}$ The basis of the oedema in cor pulmonale remains in doubt. ${ }^{7}$ There is also debate about whether right heart function in such patients is normal or depre-

Address for reprint requests: Dr W MacNee, Department of Medicine, Royal Infirmary, Edinburgh EH3 9YW.

Accepted 7 March 1983 ssed. ${ }^{89}$ An alternative explanation of the mechanism of the oedema in clinical cor pulmonale suggests that there is a fall in renal blood flow that activates the renin-angiotensin-aldosterone system, resulting in sodium and water retention. ${ }^{10-13}$

The recent introduction of radionuclide methods of assessing right ventricular performance should improve our understanding of cardiac function in clinical cor pulmonale. Such measurements have previously been reported in patients with chronic bronchitis and emphysema. ${ }^{1415}$ Relatively few of these patients, however, have had severe disturbances of arterial blood gas tensions or clinical cor pulmonale. In this study we have used multiplegated equilibrium radionuclide ventriculography to measure right and left ventricular ejection fractions (RVEF, LVEF) in patients with severe chronic bronchitis and emphysema with and without cor pulmonale, and have related the findings to the clinical and electrocardiographic indices of cor pulmonale, lung function, and arterial blood gas tensions in these patients. 


\section{Methods}

\section{SUBJECTS}

We have measured right and left ventricular ejection fractions by multiple-gated equilibrium blood pool scintigraphy in 18 control subjects $(14 \mathrm{M}, 4 \mathrm{~F}$, aged 21-63 years, mean 42 years), in 16 patients with angina (13M, 3F, aged 46-72 years, mean 58 years), and in 45 patients with chronic bronchitis and emphysema (29M and $16 \mathrm{~W}$, aged $40-81$ years, mean 59 years). The patients with chronic bronchitis and emphysema also had RVEF measured by firstpass radionuclide angiography. All 18 control subjects had been referred for investigation of atypical chest pain but had no history or clinical evidence of lung disease, and their chest radiographs and their electrocardiograms and radionuclide LVEF, both at rest and on exercise, were all normal. None of these control subjects was receiving respiratory or cardiovascular drugs at the time of study, and the subsequent clinical course showed that none had ischaemic heart disease or chronic bronchitis. The 45 patients with chronic bronchitis and emphysema had irreversible airflow limitation $\left(\mathrm{FEV}_{1} 0 \cdot 7, \mathrm{SD} \pm\right.$ 0.31 (range $0.4-2.0$ ); forced ventilatory capacity (FVC) $2 \cdot 1 \pm 0.81$ (range $0.5-3.7)$ ) and hypoxaemia $\left(\mathrm{PaO}_{2} 6.9 \pm 1.3 \mathrm{kPa}(52 \pm 10 \mathrm{~mm} \mathrm{Hg})\right.$, range 4.7 $9.6 \mathrm{kPa}(35-72 \mathrm{~mm} \mathrm{Hg})$ ), and most had a compensated respiratory acidosis $\left(\mathrm{PaCO}_{2} 6.9 \pm 1.2 \mathrm{kPa}(52\right.$ $\pm 9 \mathrm{~mm} \mathrm{Hg}$ ), range $4 \cdot 5-9.2 \mathrm{kPa}(34-69 \mathrm{~mm} \mathrm{Hg})$; arterial $\mathrm{H}^{+}$activity $42 \pm 4 \mathrm{nmol} / \mathrm{l}$, range 35-51 $\mathrm{nmol} / \mathrm{l})$. The 16 patients with angina pectoris had a history typical of angina and electrocardiographic evidence of ischaemic heart disease, but were not in heart failure and had not suffered previous myocardial infarction or lung disease. In all patients current drug treatment was continued during the study but bronchodilators were discontinued four hours before measurement of $\mathrm{FEV}_{1}$ and FVC. Arterial blood gas tensions, FEV 1 and FVC were measured while they were breathing room air; and electrocardiograms were done within 24 hours of the radionuclide study. In 12 patients pulmonary arterial pressure and cardiac output were measured at the same time as the radionuclide study was carried out, a Swan-Ganz flow-directed balloon catheter being used. Cor pulmonale was diagnosed clinically by documented evidence of ankle oedema, for which no other cause could be found, that was present at the time of study or had been found in the past. On this basis 12 patients had no cor pulmonale, 19 had had it in the past, and 14 had it at the time of study. Fourteen patients had received domiciliary oxygen for between six months and five years, for 15 hours a day at flow rates of $1-2 \mathrm{l} / \mathrm{min}$ by nasal prongs. ${ }^{16}$ Four patients had RVEF measured before and six months after 15 hours a day of such oxygen treatment. All measurements of RVEF and LVEF were made when the patients were breathing room air. The study was approved by the hospital ethical committee and the Medical Research Council's Isotope Committee, and each patient gave informed consent to the study.

\section{RADIONUCLIDE TECHNIQUES}

The details of the radionuclide techniques are described elsewhere. ${ }^{1718}$ In brief, in all studies the subjects lay supine beneath a Searle LEM gamma camera connected to a microcomputer (Cromenco Systems 3). Heart rate was derived from the ECG, which was monitored continuously throughout the study, and used to trigger, or gate, the ventriculogram. Initially, for the first-pass measurement, the gamma camera was positioned in a $20^{\circ}$ left anterior oblique projection with a $10^{\circ}$ caudal tilt; thereafter the position was changed to a $20^{\circ}$ left anterior oblique view with a $20^{\circ}$ caudal tilt to optimise separation of the right and left ventricles and right atrium, as suggested by our previous studies. ${ }^{18}$ Radioactivity from 500 sequential cardiac cycles was recorded in frame mode. The images were displayed in "movie" format and regions of interest around the right and left ventricles were chosen. After suitable background correction, as described in our previous paper, ${ }^{18}$ the ejection fraction (EF) was calculated from the equation

$$
\mathrm{EF}=\frac{\mathrm{EDC}-\mathrm{ESC}}{\mathrm{EDC}},
$$

where EDC and ESC are the counts of radioactivity within the region of interest at end diastole and end systole.

Values are given as means and standard deviations. Statistical comparisons were made with the paired $t$ test and analysis of variance.

\section{Results}

The correlation between RVEF values obtained by the first-pass and the equilibrium methods in the patients with chronic bronchitis and emphysema was $\operatorname{good}(r=0.91, p<0.001)$. As the measurement of LVEF was made by the equilibrium method, we have chosen to give the measurements of RVEF made by the same method; but the results of the study do not differ significantly whichever of the two methods of obtaining the RVEF values is used.

RIGHT VENTRICULAR EJECTION FRACTION The mean RVEF in 18 control subjects was $0 \cdot 62 \pm$ 


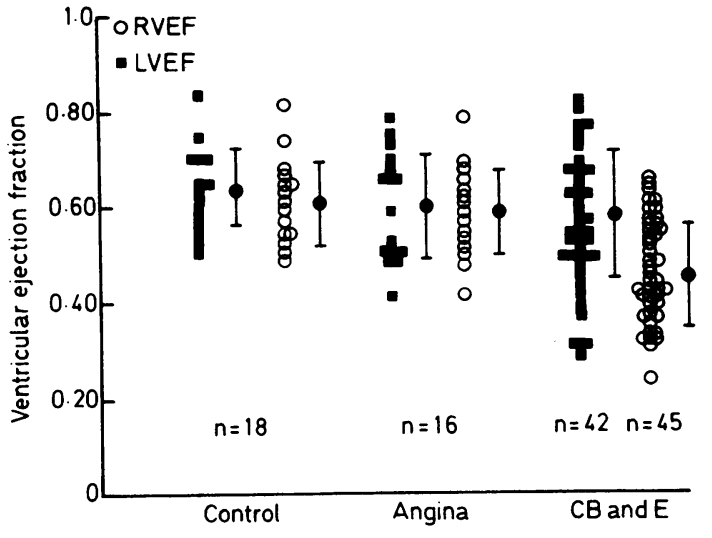

Fig 1 Right and left ventricular ejection fraction (RVEF, $L V E F)$ in control subjects and patients with angina or chronic bronchitis and emphysema (CB and E). The points are individual values for $R V E F(O)$ and $L V E F(\square)$ and the mean values for each group (O) $\pm 1 S D$ are shown. The mean $R V E F$ in patients with chronic bronchitis and emphysema is significantly lower than in controls $(p<$ 0.01).

0.09 (range $0 \cdot 50-0.83$ ) (fig 1 ). The mean RVEF in the 16 patients with angina was $0.60 \pm 0.09$ (range $0.50-0.80$ ), which was not significantly different from the value in control subjects. The mean RVEF in patients with chronic bronchitis and emphysema, however, was $0.45 \pm 0.11$ (range 0.24-0.66), which was significantly lower $(p<0.01)$ than the mean for the control subjects. Of the 45 patients with chronic bronchitis and emphysema, 29 had RVEF values below $\mathbf{0} \cdot 50$.

\section{LEFT VENTRICULAR EJECTION FRACTION}

There was no significant difference between mean values of LVEF in control subjects $(0.64 \pm 0.08)$, patients with angina $(0.60 \pm 0.11)$, and patients with chronic bronchitis and emphysema (058 \pm $0 \cdot 13$ ) (fig 1). The lowest value of LVEF in our control subjects was $0 \cdot 51$. Six patients with angina and 16 patients with chronic bronchitis and emphysema (only one of the latter having electrocardiographic evidence of ischaemic heart disease) had an LVEF below 0.50 .

The range of values of RVEF and LVEF was much wider in patients with chronic bronchitis and emphysema than in those with angina and the control subjects. In neither the control subjects nor patients with angina did values of RVEF correlate with LVEF $(r=0.275 ; p>0.1)$, whereas RVEF was significantly correlated with LVEF $(r=0.61 ; p$ $<0.01$ ) in the patients with chronic bronchitis and emphysema (fig 2). As expected, those patients with chronic bronchitis and emphysema who either had cor pulmonale at the time of study or had had it in the past (as defined previously) had values of $\mathrm{FEV}_{1}$

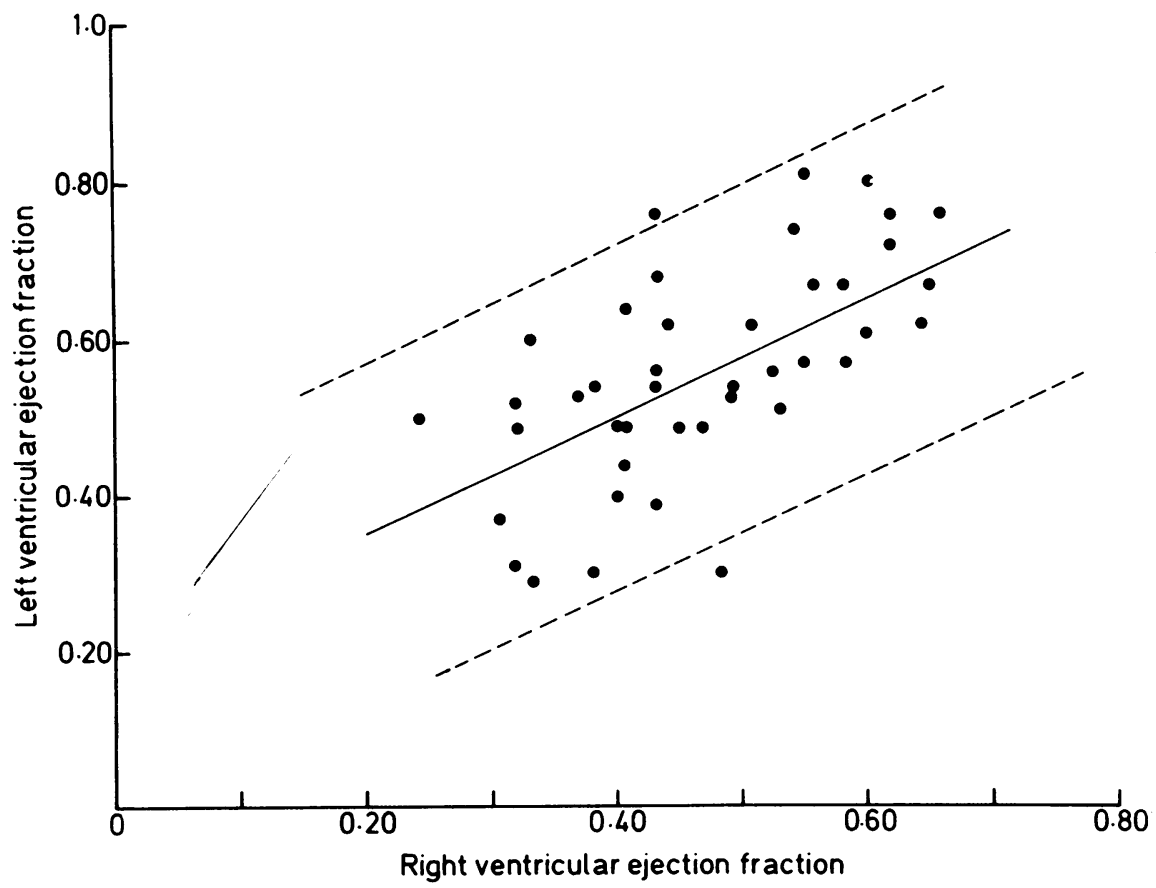

Fig 2 The correlation between right and left ventricular ejection fraction (RVEF and LVEF) in 43 patients with chronic bronchitis and emphysema $(r=0.61$, $p<0.01)$. The solid line is the least-squares fut to the data and the broken lines are the $95 \%$ confidence limits. 
and $\mathrm{PaO}_{2}$ which were significantly lower $(\mathrm{p}<0.01)$ and values of $\mathrm{PaCO}_{2}$ significantly higher $(\mathrm{p}<0.01)$ than those patients without cor pulmonale (table 1 ). RVEF was lower $(p<0.001)$, however, only in those who had cor pulmonale at the time of study,

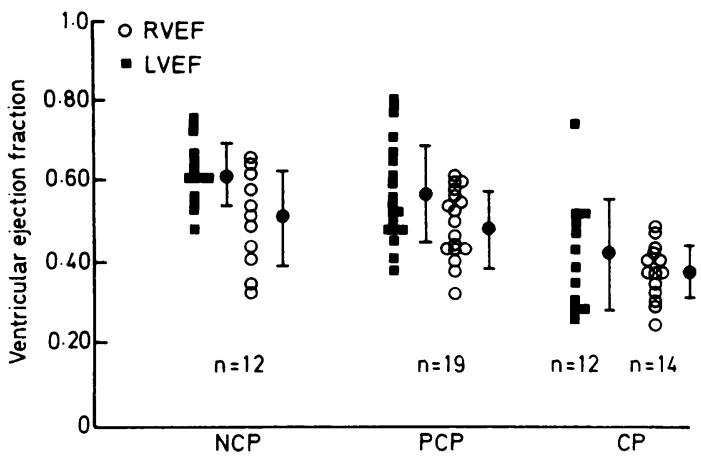

Fig 3 Right and left ventricular ejection fraction (RVEF and $L V E F)$ in patients with chronic bronchitis and emphysema who had no cor pulmonale (NCP), who had had cor pulmonale in the past (PCP), and who had cor pulmonale at the time of study $(C P)$. The points are individual values for RVEF (O) and LVEF ( $\square$ ). The mean values for each group (O) $\pm 1 S D$ are shown (NCP v PCP, $N S$; $N C P \vee C P, p<0.01)$.

(a)
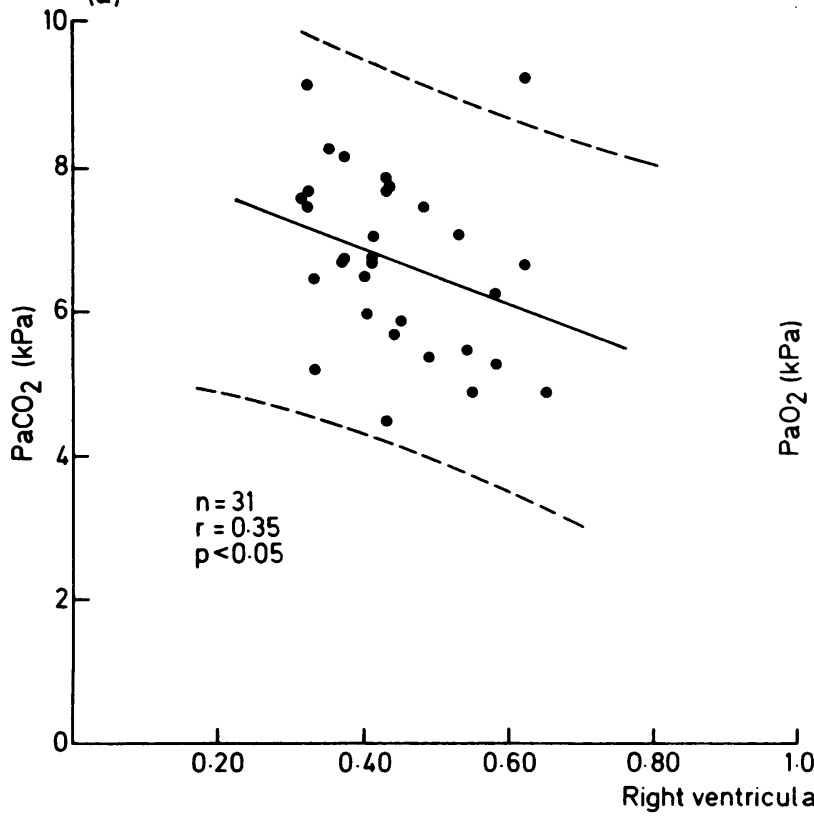

Right ventricular ejection fraction
Table 1 Blood gas tensions and $F E V_{1}$ in 45 patients with chronic bronchitis and emphysema

\begin{tabular}{llll}
\hline Patient group & $\begin{array}{l}\mathrm{PaO}_{2} \\
(\mathrm{kPa})\end{array}$ & $\begin{array}{l}\mathrm{PaCO} \\
(\mathrm{kPa})\end{array}$ & $\begin{array}{l}\mathrm{FEV} \\
(\mathrm{l})\end{array}$ \\
\hline $\begin{array}{l}\text { No cor pulmonale } \\
\text { Previous cor } \\
\text { pulmonale }\end{array}$ & $8.1 \pm 1.3$ & $6.2 \pm 0.8$ & $0.9 \pm 0.4$ \\
$\begin{array}{c}\text { Cor pulmonale } \\
\text { present }\end{array}$ & $6.7 \pm 1.2^{* * *}$ & $6.9 \pm 1.3^{* *}$ & $0.7 \pm 0.3^{* *}$ \\
\hline
\end{tabular}

For the definition of cor pulmonale see text. The data are means \pm 1 standard deviation. ${ }^{*}=p<0.05 ;^{* *}=p<0.01 ;^{* * *}=p<$ 0.001 . The $p$ values relate to significant differences from the results in those with no cor pulmonale.

Conversion: SI to traditional units-Arterial oxygen tension $\left(\mathrm{PaO}_{2}\right)$ and arterial carbon dioxide tension: $1 \mathrm{kPa}=7.5 \mathrm{~mm} \mathrm{Hg}$.

and not in those patients who had had it in the past. None of the 14 patients with cor pulmonale at the time of study had a normal RVEF $(>0.50)$ whereas nine of the 19 patients with past cor pulmonale had a low value of RVEF (fig 3 ).

LVEF was significantly lower $(p<0.001)$ in those patients with cor pulmonale at the time of study than in those with no previous cor pulmonale and those who had had it previously (fig 3 ). In 16 patients with chronic bronchitis and emphysema LVEF was lower

Fig 4 Correlation between right ventricular ejection fraction (RVEF) and (a) arterial oxygen tensions (Pao, and (b) arterial carbon dioxide tensions ( $\mathrm{PacO}_{2}$ ) measured when they were breathing air in 31 patients with chronic bronchitis and emphysema. The solid lines are the least-squares fit to the data and the broken lines are the $95 \%$ confidence limits. 


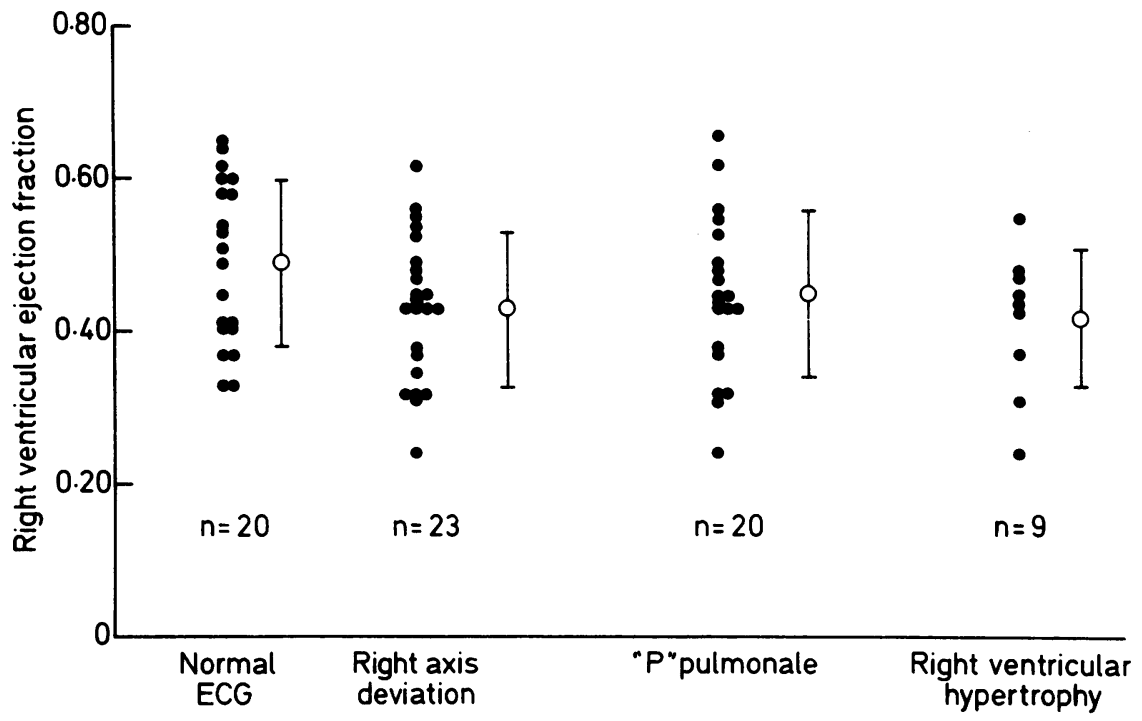

Fig 5 Comparison of the electrocardiographic findings and right ventricular ejection fraction (RVEF) in 45 patients with chronic bronchitis and emphysema. The points are individual values (O), with the mean $R V E F$ for each electrocardiographic category $(O) \pm 1 S D$.

than normal $(<0 \cdot 50)$. None of these had hypertension; one had ischaemic heart disease, eight had cor pulmonale at the time of study, six had had it in the past, and only two had had no previous cor pulmonale. All patients with a low LVEF also had a low RVEF.

In the patients with chronic bronchitis and emphysema there was no significant correlation between RVEF and either FEV $(r=0 \cdot 16)$, percentage of predicted $\mathrm{FEV}_{1}(\mathrm{r}=0 \cdot 17)$, or FVC $(\mathrm{r}=$ $0.23)$ ( $p>0.1$ in each case). In 12 patients in whom pulmonary arterial pressure was measured at the time of the radionuclide study RVEF did not correlate with the mean or the systolic pulmonary arterial pressure $(r=0.15, p>0.5)$ or the pulmonary vascular resistance $(r=0.09, p>0.5)$. There was, however, a significant correlation between RVEF and $\mathrm{PaO}_{2}(\mathrm{r}=0.51, \mathrm{p}<0.01)$ and between RVEF and $\mathrm{PaCO}_{2}(\mathrm{r}=-0.35, \mathrm{p}<0.05)$, but not between RVEF and arterial hydrogen ion concentration $(r=$ $0 \cdot 15, p>0.05$ ) (fig 4) in 31 patients who were not receiving long-term oxygen treatment (RVEF 0.44 $\pm 10, \mathrm{PaO}_{2} 7.3 \pm 1.3 \mathrm{kPa}(54.6 \pm 9.6 \mathrm{~mm} \mathrm{Hg})$. There was no significant correlation between RVEF and $\mathrm{PaCO}_{2}$ and $\mathrm{PaCO}_{2}$ in the 14 patients who were receiving long-term oxygen treatment (RVEF 0.51 $\left.\pm 0 \cdot 11, \mathrm{PaO}_{2} 6.2 \pm 1 \cdot 0 \mathrm{kPa}(46.5 \pm 7.5 \mathrm{~mm} \mathrm{Hg})\right)(\mathrm{r}$ $=0.09, \mathrm{p}>0.1)$.

In the patients with chronic bronchitis and emphysema there was a significant correlation between LVEF and $\mathrm{PaO}_{2}(\mathrm{r}=0.64, \mathrm{p}<0.001)$ in the 31 patients who were not receiving long-term oxygen treatment, but no correlation between LVEF and any of the other variables.
Four patients were studied before and six months after the start of treatment with low-flow oxygen for 15 hours in every 24 hours. Three patients who had an abnormal RVEF (mean 0.35) before oxygen treatment had a normal RVEF (mean 0.53 ) after six months' treatment. One patient who had a normal RVEF $(0.55)$ showed no change in RVEF after this period of oxygen treatment.

Electrocardiographic evidence of cor pulmonale (fig 5) did not distinguish patients with normal and low values of RVEF.

\section{Discussion}

The complex geometry of the right ventricle makes angiographic assessment of right ventricular volumes difficult, and although stroke volumes determined by the angiographic and the thermodilution techniques have been shown to be correlated ${ }^{19}$ contrast angiography has not been widely applied in the assessment of right ventricular performance. Similar geometric constraints apply to attempts to analyse right ventricular performance by echocardiography. As radionuclide techniques do not depend on a knowledge of the geometry of the cardiac chambers, and volumes of the chambers are directly proportional to radioactive counts, these methods have great attraction in the assessment of right ventricular performance. Most radionuclide studies of the right ventricle have been carried out with a first-pass technique, which allows optimal separation between right atrium and right ventricle. Count rate limitations, however, make this technique less suited to conventional gamma cameras. We have modified 
the equilibrium blood-pool technique first described by Maddahi, ${ }^{17}$ and have shown that results correlate well with those obtained with the first-pass method. ${ }^{18}$ In the presentation of results in this study we have used the measurements derived from the equilibrium technique, as the left ventricular ejection fraction was also determined by this technique. The results would be virtually identical, however, if the values obtained from the first-pass technique had been used. The range of right ventricular ejection fractions in our 18 control subjects was from 0.50 to 0.83 , similar to values in previous control subjects obtained by a first-pass technique, ${ }^{14} 1520$ but higher than the normal range obtained by Maddahi ${ }^{17}$ $(0 \cdot 39-0 \cdot 57)$ using an equilibrium technique. Our LVEF values were similar to the results obtained in control subjects by either first-pass or equilibrium methods. ${ }^{1415172021}$ We found no significant difference in either right or left ventricular ejection fraction between control subjects and those with angina pectoris.

We can confirm that right ventricular ejection fraction varies widely in chronic bronchitis and emphysema, but is significantly lower than in control subjects, thus confirming the results of earlier studies. ${ }^{141520}$ All of our patients with chronic bronchitis and emphysema were hypoxic $\left(\mathrm{PaO}_{2} 6.9 \pm 1 \cdot 3\right.$ $\mathrm{kPa}(51.6 \pm 9.8 \mathrm{~mm} \mathrm{Hg}))$, and 33 of the 45 patients were hypercapnic. Most (33) had cor pulmonale at the time of study or had had it previously. Despite having these severe abnormalities of respiratory function 16 of the patients had a normal right ventricular ejection fraction, suggesting that right ventricular function (as reflected by this measurement) is maintained until a late stage of the disease. The left ventricular ejection fraction was normal in most of the patients with chronic bronchitis and emphysema but was below normal in 16 of the 45 patients. Previous workers have not reported a correlation between the ejection fractions of the right and left ventricles in patients with chronic bronchitis and emphysema, ${ }^{1422} 23$ but this may be related to selection of patients. Berger et al studied patients with chronic obstructive lung disease, of whom $28 \%$ had cor pulmonale ${ }^{14}$; whereas in this present study $73 \%$ had cor pulmonale. This, coupled with the fact that abnormalities of arterial blood gas tensions in our patients were more severe, could explain why the correlations between right and left ventricular ejection fraction were more obvious. Differences in definition of the clinical syndrome of cor pulmonale are important in this context. Whereas Berger made ECG evidence of right ventricular hypertrophy a prerequisite for this diagnosis, ${ }^{14}$ we have not assumed that cor pulmonale exists only with this electrocardiographic feature in patients with chronic bronchitis and emphysema. Pitting ankle oedema, for which no other cause can be found, in a patient with chronic bronchitis and emphysema is the basis of our clinical diagnosis of cor pulmonale as the level of the jugular venous pressure is less reliable in patients with severe airflow obstruction. By this criterion we found that the electrocardiographic evidence of right ventricular hypertrophy did not separate those patients with clinical cor pulmonale from those without cor pulmonale, nor did it correlate with the right ventricular ejection fraction. The lack of correlation between electrocardiographic features and clinical evidence of cor pulmonale has been noted by previous workers. ${ }^{324}$

Previous studies with invasive techniques have presented conflicting data on left ventricular function in chronic bronchitis and emphysema. ${ }^{85}$ Our data suggest that the degree of depression of both right and left ventricular function relates to arterial hypoxaemia, but this applies only to patients who were not receiving long-term oxygen treatment (arterial blood gas tensions and all radionuclide studies were performed when the patients were breathing room air). The lack of correlation between right ventricular ejection fraction and $\mathrm{PaO}_{2}$ and $\mathrm{PaCO}_{2}$ in patients receiving long-term oxygen treatment may be due to the higher $\mathrm{PaO}_{2}$ attained by these patients for 15 hours of each day. Although previous workers ${ }^{14} 15$ have not distinguished patients who were receiving long-term oxygen, this group may be a separate population as the treatment is known to affect pulmonary haemodynamics. ${ }^{1626} \mathrm{Our}$ results suggest that $\mathrm{PaCO}_{2}$ and to a lesser extent (in the case of right ventricular ejection fraction) $\mathrm{PaCO}_{2}$ are more important in determining right and left ventricular ejection fraction in patients with chronic bronchitis and emphysema. Our preliminary results on the effects of long-term oxygen on right ventricular ejection fraction in this study are similar to those reported by Ellis $e a^{27}$ and are encouraging, although there is disagreement about whether the improvement produced by oxygen treatment is a result of acute reduction of right ventricular afterload $^{1627}$ or due to a more long-term effect of such treatment on pulmonary arterial structure.

Ejection phase indices are dependent on both the preload and afterload on the ventricle and pulmonary hypertension would be expected to reduce the right ventricular ejection fraction. We were surprised that we could not correlate changes in right ventricular ejection fraction with pulmonary arterial pressure or pulmonary vascular resistance in 12 of our patients with chronic bronchitis and emphysema. Similar findings, however, have been reported by Ellis et al. ${ }^{27} \mathrm{An}$ increase in pulmonary arterial pressure could be the main contributor to 
the reduction in ejection fraction in acute cor pulmonale, but the left ventricle is not then subjected to an increased afterload and this would not explain the reduction in left ventricular ejection fraction in our patients with cor pulmonale at the time of study.

In conclusion, we have used gated equilibrium blood-pool radionuclide ventriculography to show that the right ventricular ejection fraction is reduced in patients with chronic bronchitis and emphysema and is further reduced, along with a concomitant reduction in left ventricular ejection fraction, in those patients who have cor pulmonale at the time of study. As cardiac output and stroke volume can also be measured by radionuclide methods ${ }^{28}$ absolute determinations of end-diastolic and end-systolic volumes may be made, and by relating these to intracardiac pressures the mechanics of the right ventricle in cor pulmonale can be understood more clearly.

\section{References}

' Dornhorst AC. Respiratory insufficiency. Lancet $1955 ;$; :1185-7.

${ }^{2}$ Thomas AJ. Chronic pulmonary heart disease. Br Heart J 1972;34:653-7.

${ }^{3}$ Fishman AP. Chronic cor pulmonale. Am Rev Respir Dis 1976;114:775-94.

${ }^{4}$ Renzetti AD jun, McClement JH, Litt BD. The Veterans Administration Co-operative Study on Pulmonary Function. III Mortality in relation to respiratory function in chronic obstructive pulmonary disease. Am J Med 1966;41:115-29.

${ }^{5}$ Weitzenblum E, Loiseau A, Hurth C, Mirhom R, Rasaholinjanahory J. Course of pulmonary haemodynamics in patients with chronic obstructive pulmonary disease. Chest 1979;75:656-62.

- Middleton HC, Peake MD, Howard P. Hypoxaemia in chronic bronchitis. Thorax 1979;34:313-6.

${ }^{7}$ Richens JM, Howard P. Oedema in cor pulmonale. $\mathrm{Cli}$ Sci 1982;62:255-9.

${ }^{8}$ Khaja F, Parker JO. Right and left ventricular performance in chronic obstructive lung disease. Am Heart J 1971;82:319-27.

${ }^{9}$ Jezek V, Schrijen F. Left ventricular function in chronic obstructive lung disease with and without cardiac failure. Cli Sci Mol Med 1973;45:267-79.

${ }^{10}$ Platts MM, Hammond JDS, Stuart-Harris CH. A study of cor pulmonale in patients with chronic bronchitis. $Q$ $J$ Med 1960;29:559-74.

"Aber GM, Bishop JM. Small changes in renal function, arterial gas tensions and acid-base state in patients with chronic bronchitis and oedema. Cli Sci 1965;281:511-25.

${ }_{12}$ Tomaszewski J, Kowalewski J, Wrukowska M. Plasma activity in patients with chronic cor pulmonale syndrome. Polish Medical Science and History Bulletin
1975;15:207-11.

${ }^{13}$ Stuart-Harris CH, Mackinnon J, Hammond JDS, Smith WD. The renal circulation in chronic pulmonary disease and pulmonary heart failure. $Q J M e d$ 1956;25:389-405.

${ }^{14}$ Berger HJ, Matthay RA, Lohe J, Marshall RC, Gottschalk A, Zaret BL. Assessment of cardiac performance with quantitative radionuclide angiography. Right ventricular ejection fraction with reference to findings in chronic obstructive pulmonary disease. $\mathrm{Am}$ J Cardiol 1978;41:897-905.

${ }^{15}$ Slutsky RA, Acherman W, Karliner JS, Ashburn WL, Moser KM. Right and left ventricular dysfunction in patients with chronic obstructive lung disease. Assessment by first-pass radionuclide angiography. Am J Med 1980;68:197-205.

${ }^{16}$ Medical Research Council. Long-term domiciliary oxygen therapy in chronic hypoxic cor pulmonale complicating chronic bronchitis and emphysema. Lancet $1981 ; \mathrm{i}: 681-6$.

${ }^{17}$ Maddahi J, Berman DS, Dale T, et al. A new technique for assessing right ventricular ejection fraction using rapid multiple-gated equilibrium cardiac blood pool scintigraphy. Circulation 1979;60:581-9.

${ }^{18}$ Xue QF, MacNee W, Flenley DC, Hannan WJ, Adie CJ, Muir AL. Can right ventricular performance be assessed by equilibrium radionuclide ventriculography Thorax; 38:486-93.

${ }^{19}$ Gentzler RD, Briselli MF, Gault GH. Angiographic estimation of right ventricular volume in man. Circulation 1974;50:324-30.

${ }^{20}$ Matthay RA, Berger HJ, Davies RA, et al. Right and left ventricular exercise performance in chronic obstructive pulmonary disease. Radionuclide assessment. Ann Intern Med 1980;93:234-9.

${ }^{21}$ Burrow R, Strauss HW, Singleton R, et al. Analysis of left ventricular function from multiple-gated acquisition cardiac blood pool imaging: comparison to contrast angiography. Circulation 1977;56:1024-8.

${ }^{22}$ Steele P, Ellis J, Van Dyke D, Sutton F, Creagh E, Davis $H$. Left ventricular ejection fraction in severe obstructive lung disease. Am J Med 1975;59:21-7.

${ }^{23}$ Kline L, Crawford M, MacDonald W, Schelbert H, O'Rourke R. Non-invasive assessment of left ventricular performance in patients with chronic obstructive lung disease. Chest 1977;72:558-64.

${ }^{24}$ Padmavati S, Raizada V. The electrocardiogram in chronic cor pulmonale. Br Heart J 1973;34:658-67.

${ }^{25}$ Burrows B, Kettel L, Nides A, et al. Patterns of cardiovascular dysfunction in chronic obstructive lung disease. $N$ Engl J Med 1972;286:912-7.

${ }^{26}$ Nocturnal Oxygen Therapy Trial Group. Continuous or nocturnal oxygen therapy in hypoxaemic chronic obstructive lung disease. Ann Intern Med 1980;93:391-8.

${ }^{27}$ Ellis JH Jr, Kirch D, Steele PP. Right ventricular ejection fraction in severe chronic airway obstruction. Chest 1977;71:281-2.

${ }^{28}$ Hannan WJ, Vojacek J, Dewhurst NG, Muir AL. The sequential measurement of ventricular volumes and cardiac output by radionuclides. Clinical, Physical and Physiological Measurement 1980;1:125-34. 